\title{
Discovery of cockroach specimens of the genus Squamoptera (Ectobiidae: Pseudophyllodromiinae) from Okinawa, Japan, showing wing polymorphism
}

\author{
Komatsu, N. ${ }^{1}$, Bando, N. ${ }^{2}$, Uchida, A. ${ }^{3}$, Ooi, H.K. ${ }^{3,4^{*}}$ \\ ${ }^{1}$ Civil International Corporation, 1-10-14 Kitaueno, Taito, Tokyo 110-0014 Japan \\ ${ }^{2}$ Super Buddies, 422 Nosoko, Ishigaki, Okinawa 907-0333 Japan \\ ${ }^{3}$ Laboratory of Parasitology, Faculty of Animal Health Technology, Yamazaki University of Animal Health Technology, 4-7-2 Minami-osawa, Hachioji, \\ Tokyo 192-0364 Japan \\ ${ }^{4}$ Laboratory of Parasitology, School of Veterinary Medicine, Azabu University, 1-17-71 Fuchinobe, Sagamihara, Kanagawa $252-5201$ Japan \\ *Corresponding author: hkooi@azabu-u.ac.jp
}

\section{ARTICLE HISTORY}

Received: 15 December 2020

Revised: 2 February 2021

Accepted: 2 February 2021

Published: 31 July 2021

\begin{abstract}
Cockroach specimens of the genus, Squamoptera were collected from the Iriomote island of Okinawa prefecture, Japan. The morphological features of the specimens were characterized as having a white band on the dorsal surface of its thorax, its tegmen reduced into a tiny scale-like structure and the hindwing was absent. Ocelli was also absent and the small compound eyes not extending to apex of the head nor to the frontal face but extend further lower than the base of the antennae. When the specimens were reared in the laboratory, besides the short wing form, the long wing form began to appear in the rearing colony. In our reproductive biological study, we observed that hatching of the ootheca from the short wing female takes about 30 days, with an average of 6.6 nymphs being hatched from one ootheca. The male to female ratio of the offspring was 36:30. However, the frequency appearance of the offspring from the ootheca of the short wing female was $98.5 \%$ short wing and $1.5 \%$ long wing form. Our specimens occasionally show body polymorphism in the form of individuals having long wings instead of the usual short one. The long wing form does not show the white band on the dorsal surface of its thorax.
\end{abstract}

Keywords: Cockroach; Pseudophyllodromiinae; Squamoptera; Japan; wing polymorphism.

\section{INTRODUCTION}

Despite having a small land area, Japan has a comparatively high biodiversity in cockroach fauna. Asahina (1991) recorded a total of 25 genera comprising of 52 species of cockroaches in Japan. Later, Komatsu et al. $(2014,2015)$ added Sigmella schenklingi (Karny, 1915) and Pycnoscelus indicus (Fabricius, 1775) for Japan as a new geographical record. Moreover, new geographical record for Neostylopyga rhombifolia (Stoll, 1813) on Iwojima and Opisthoplatia orientalis (Burmeister) on Chichijima in the Ogasawara island chain were also reported (Komatsu et al., 2013). Presently, the cockroach fauna in Japan has been reported to consist of 61 species in 29 genera and belonging to 6 families (Asahi et al., 2016, Djernæs, 2018, Komatsu et al., 2021, Yanagisawa et al., 2020; 2021). In this paper, we report a newly discovered cockroach specimen belonging to the genus Squamoptera, in Japan, that show wing polymorphism. We also examined the frequency occurrence of different polymorph and the reproductive biology of the collected specimens.

\section{MATERIALS AND METHODS}

\section{Collection of specimens}

Several small size cockroaches were collected on Iriomote Island at Uehara, Taketomicho, Yaeyamagun, Okinawa, Japan $\left(24.3890824^{\circ} \mathrm{N}, 123.814527^{\circ} \mathrm{W}\right)$ on April 17, 2012. The specimens were found under the dried bark of a rotting vertical tree in the forest. At the time of the collection, the specimens were small and showed a white band on the dorsal surface of the thorax. They gave the impression of being the first nymphal stage of genus Periplaneta. Several specimens were collected live, put into plastic film roll cases and brought back to our laboratory to be reared and bred. Subsequent rearing of these small size cockroaches produced morphologically different individuals.

Rearing and breeding of the cockroaches in the laboratory The cockroaches were reared in a plastic container with the dimension $300 \mathrm{~mm} \times 195 \mathrm{~mm} \times 205 \mathrm{~mm}$ (Suzuki Seisaku Co., Japan). The bedding were made up of $30 \mathrm{~mm}$ thick coconut 
husk fiber mat (Mitani Co., Japan). Holes were made in the container lid for aeration. The cockroaches were fed sphagnum (peat moss) MF (Oriental Koubo Co., Japan) and given water ad libitum. The whole container was placed in an incubator (Sanyo Co., Japan), with temperature set at $25-28^{\circ} \mathrm{C}$, humidity at $50-70 \%$ and left under natural light condition. The water supply bottle was observed every day and if the sphagnum were dried, water mist was sprayed on it. The ootheca that were produced were individually transferred to a plastic container of diameter $75 \mathrm{~mm}$ and height $40 \mathrm{~mm}$. The offspring were reared under the same condition as their parents. Days taken for the hatching of the eggs in the ootheca, the ratio of the hatched eggs, numbers of male and female offspring produced and the process of the wing development were noted.

\section{Preparation of specimen for microscopy}

The specimens used for observation of the morphological structures were laboratory reared individuals. The cockroaches were first killed in $70 \%$ ethanol followed by immersion in $10 \%$ potassium hydroxide for $24 \mathrm{hr}$. After washing with water, they were then transferred to the Hoyer medium (Shiga Konchyu Fukyu Co., Japan). The specimens were then mounted on a slide glass for microscopic examination of their detailed structures.

\section{RESULTS}

The specimens collected were found to belong to the genus Squamoptera Bruijning, based on the following genus diagnosis, with the exception of the wings: Eyes reduced. Anteroventral margin of fore femur with a dense row of piliform spinules terminating in 1 or 2 large spines [Type C1, as proposed by Roth (1996)]; posteroventral margin unarmed or with a few large spines; anterior and posterior ventral margins of mid and hind femora with only a few large spines; pulvilli absent from all tarsomeres and arolia absent. Male genital hook on the right side.

Among our collected specimens, besides the short wing form, long wing form could be observed after rearing in the laboratory. Description of the short wing form and longwing form of our specimens are as follows.

\section{Short wing form (Figure $1 \mathrm{~A}$ )}

Body length of male, $5.5-6.0 \mathrm{~m}$ and female, $6.2-7.0 \mathrm{~mm}$. Body are ellipsoidal in both sexes. Whole body brownish black except for anterior edge of metanotum, lateral edge of thoracic segments, as well as eggs, which are light brownish yellow. Present of a narrow white band running along the anterior margin of each abdominal tergum (Figure 1A). Ocelli absent. Compound eyes are small, not well developed and not extending to apex of the head nor to the frontal face but extend further lower than the base of the antennae. Pronotum is trapezoid, brown at center with black-brown patches irregularly distributed and lateral edge being translucent and light yellowish brown in both sexes. Cercus made up of 9 yellowish brown segments with setae on each segment.

The subgenital plate of the male is trapezoidal with small V-shape notch at middle of posterior margin. The anal style is short with three spines at apex. In the female, subgenital plate is round with numerous short spines on its surface

In both sexes, abdominal tergum lack the secretory gland opening and sparse row of spines present on the posterior margin of each tergum. Tegmen is reduced to a tiny scalelike structure, just about reaching only to the middle of mesonotum and about $1 \mathrm{~mm}$ in length. Hindwing absent. All legs are light yellowish brown and spines arrangement on the right front femur are of C1 type. Arolia absent and the claws are symmetrical. Genital hook is the on right side.

Long wing form (Figure 1B).

Body length of male and female, $6.5-7.0 \mathrm{~mm}$. Tegmen length of male and female, $6.5-7.0 \mathrm{~mm}$. Almost all of the morphological features of the long-wing form are similar to those of the short-wing form. However, the tegmen, epicranial fissure line and pronotal dorsum are the exceptions. The fissure line extending from the compound eyes to the parietal region as seen in the short-wing form, is absent in the longwing form. The pronotum is trapezoidal in the short-wing form, but disk-shaped in the long-wing form.

In both the long wing form of the male and female, the forewing and the hindwing are well developed. Sub-costa (Sc) vein do not branch and several veins crisscrossed the entire wing to form a network of veins. Surface of wing is covered by an undulating skin-like structure which is blackish brown. Veins in the hindwing are simple but showed a big difference among the individuals. As in the forewing, veins in the hind wing also crisscrossed the wing to form a network of veins.

\section{Study on the reproductive biology of our specimens}

Ten oothecae were obtained from five short wing females. After eggs were deposited into the ootheca, the latter was laid without being rotated (Figure 1C). Each ootheca contains 6 to 8 eggs and it took 29 to 31 days to hatch. Whenever a long

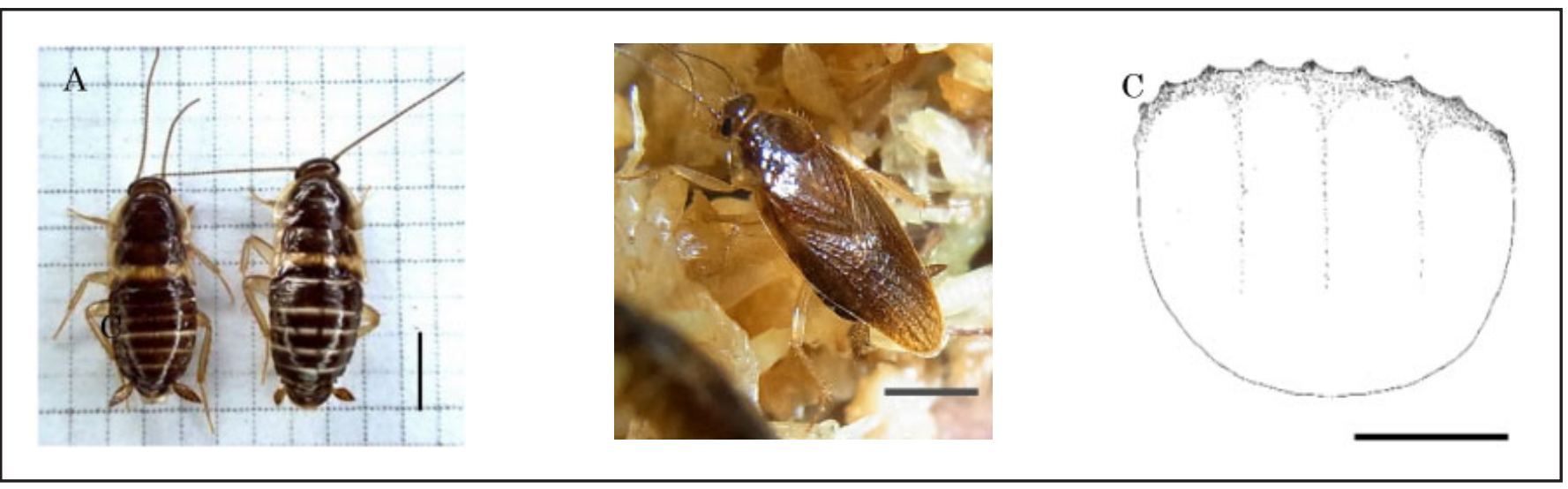

Figure 1. A-C: Squamoptera sp. from Okinawa. A: Live specimen, left is male and right is female. Scale bars: $2 \mathrm{~mm}$. B: Male of long wing form. Scale bars: $2 \mathrm{~mm}$. C: Ootheca. Scale bars: $1 \mathrm{~mm}$. 
Table 1. Ratio of long wing form to short wing form per birth from the ootheca of long wing female of Squamoptera sp.

\begin{tabular}{|c|c|c|c|c|c|c|}
\hline \multirow{2}{*}{ Ootheca No. } & \multirow{2}{*}{ No. of days to hatching } & \multirow{2}{*}{ No. of offsprings hatched } & \multicolumn{2}{|c|}{ Short wing form } & \multicolumn{2}{|c|}{ Long wing form } \\
\hline & & & Male & Female & Male & Female \\
\hline 1 & 31 & 6 & 3 & 3 & 0 & 0 \\
\hline 2 & NA & 8 & 5 & 3 & 0 & 0 \\
\hline 3 & NA & 7 & 4 & 3 & 0 & 0 \\
\hline 4 & NA & 5 & 1 & 4 & 0 & 0 \\
\hline 5 & NA & 6 & 1 & 5 & 0 & 0 \\
\hline 6 & NA & 6 & 3 & 3 & 0 & 0 \\
\hline 7 & NA & 8 & 6 & 2 & 0 & 0 \\
\hline 8 & 29 & 5 & 3 & 2 & 0 & 0 \\
\hline 9 & NA & 7 & 4 & 3 & 0 & 0 \\
\hline 10 & 31 & 8 & 5 & 2 & 1 & 0 \\
\hline Total & & 66 & 35 & 30 & 1 & 0 \\
\hline
\end{tabular}

NA: Not available.

wing specimen was observed, it was separated from the colony. All the long wing form specimens were kept together. Hatching took about 30 days ( $n=3,29-31$ days). An average of 6.6 nymphs was hatched from one ootheca, with the male to female ratio as $36: 30$. Frequency of appearance of the longwing form offspring was only $1.5 \%$ from the ootheca of the female short wing form (Table 1). However, we also found that females of the long wing form also be observed in the rearing containers where they were reared in groups. This indicates that the long wing form can occur as males and also females.

\section{DISCUSSION}

The genus Paratemnopteryx has also been reported to express wing polymorphism in some species. Specimens of that genus have been reported to have a mixture of large and reduced winged specimens, depending on their habitat (Bell et al., 2007). Thus, wing polymorphism is not considered a definitive criterion for the taxonomy of this genus as well as the species. In the description of our specimens, other than the wing polymorphism, the major features of our specimens were in general accordance to that described for the genus Squamoptera.

The genus Squamoptera was established by Bruijning (1948) and catalogued by Princis (1969) as one species, S. fulva, that was recorded worldwide. Later, two species, namely, S. zinmani and S. philippinensis, were added by Roth (1996). The specimens described in our paper is also the first record of Squamoptera from Japan. To date, the genus Squamoptera has been reported to consist of only three species, namely, S. philippinensis, S. fulva and S. zinmani.

S. philippinensis, has been found only in females, with eyes reduced, interocular space less than the distance between antennal sockets. It has a parabolic pronotum and is characterized by its tegmina length being comparatively short, with the apical edge convexly rounded and reaching approximately to the middle of the second abdominal tergum. S. fulva has pronotum with a pair of shallow depressions on the distal half of the disk and its tegmina length reaching to about the 6th segment of the abdominal tergum. S. zinmani has pronotum that is subparabolic, flat, disk without any depressions and its tegmina length reaching to about the 7 th segment of the abdominal tergum. The pronotum of our specimens is trapezoid and the tegmen is dimorphic in both sexes. In short the wing form, tegmina length was very short reaching only to the middle of mesonotum, while in the long wing form, it extended beyond the tip of the last abdominal tergum. From these differences, our specimens may actually be a new species of this genus. Since we have a rearing colony, genetic studies will further be conducted to confirm the validity of this new species.

Among the species in the order Blattodea, the appearance of the long-wing form individual in Nocticola uenoi uenoi Asahina, 1974 has been reported (Asahi et al., 2016). However, that report only noted the presence of the long wing male specimen but not the female ones. In our reproductive biological study, we were able to observe the appearance of both the male and female specimens of the long wing form in our rearing population. Moreover, we also observed that $1.5 \%$ of the offsprings produced by the short wing female specimen were that of the long wing form individuals. The ability of the female to produce individuals with wing polymorphism needs further investigation, especially on the switching of the gene expression for the formation of the wings.

Factors leading to the appearance of long wing individual has not yet been determined but it was observed that when the population density of a thriving colony become high, the long wing form began to appear. It is well known that among the desert locust Schistocerca gregaria Forsskål 1775 , individuals with long wing that can fly began to appear when there was an increase in its population (Roffey \& Popov, 1968). It is also possible that our specimens might have also adopted the same strategy of mutation to help in dispersing of its individuals in an overcrowded colony. Conversely, when the situation becomes amicable, this cockroach might have reverted to the short wing form becoming more dominant.

\section{ACKNOWLEDGEMENTS}

We thank Dr. Kazuki Ogata, Dr. Minoru Mihara and Dr. Toshihiko Hayashi of the National Institute of Infectious Diseases for helpful advice.

\section{Conflict of interest}

The authors declare that they have no conflict of interest. 


\section{REFERENCES}

Asahi, K., Endo, T. \& Komatsu. N. (2016). Blattodea. Orthoptera. In: The Standard of Polyneoptera in Japan, Orthopterological Society of Japan (editors). Tokyo: Gakken Plus, pp. 206-227.

Asahina, S. (1991). Blattaria of Japan. Tokyo: Nakayama Shoten Publisher, pp. 1-253.

Bell, W.J., Roth, L.M. \& Nalepa, C.A. (2007). Cockroaches: ecology, behavior, and natural history. Maryland: Johns Hopkins University Press, pp. 1-230.

Bruijning, C.F.A. (1948). Studies on Malayan Blattidae. Zoologische mededeelingen 29: 1-174.

Djernæs, M., 2018. Biodiversity of Blattodea- the Cockroaches and Termites. In: Insect Biodiversity: Science and Society, Foottit, R.G. \& Adler, P.H. (editors) Vol. 2, First edition. Chichester West Sussex, Wiley \& Sons Ltd., pp. 359-377. https://doi.org/10.1002/9781118945582.ch14

Komatsu, N., lio, H. \& Ooi, H.K. (2021). A new species of cockroach, Periplaneta gajajimana sp. nov., collected in Gajajima, Kagoshima Prefecture, Japan. Tropical Biomedicine 38: 48-52. https://doi.org/10.47665/tb.38.2.036

Komatsu, N., Kawakami, Y., Banzai, A., Ooi, H.K \& Uchida, A. (2014). Cockroaches collected and newly recorded species Sigmella schenklingi in Kagoshima Prefecture in winter season. Pestology 29: 1-5. https://doi.org/10.24486/ pestology.29.1_1

Komatsu, N., Kawakami, Y., Banzai, A., Ooi, H.K. \& Uchida, A. (2015). Species clarification of Ogasawara cockroaches which inhabit Japan. Tropical Biomedicine 32: 98-108. https://drive.google.com/file/d/0B75lcx0mfp20Z0t 3a1FrdXI0aWM/view ?resourcekey=0-oZPDKvB1B1A_ QITI4VaPCg
Komatsu, N., Kishimoto, T., Uchida, A. \& Ooi, H.K. (2013). Cockroach fauna in the Ogasawara Chain Islands of Japan and analysis of their habitats. Tropical Biomedicine 30: 141151. https://drive.google.com/file/d/0B75lcx0mfp2OMjJ $5 Z 3 Q 0 Q X R y U n c / v i e w$ ? resourcekey=0-nkG584vnQqjdMR $5 \mathrm{dF} 4 \mathrm{oCeQ}$

Princis, K. (1969). Orthopterorum Catalogus, Pars 13. In: Blattariae: Subordo Epilamproidea, Fam.: Blattellidae. Beier, M. (editor). Hague, pp. 713-1038.

Roffey, J. \& Popov, G.B. (1968). Environmental and behavioural processes in a desert locust outbreak. Nature 219: 446450. https://doi.org/10.1038/219446a0

Roth, L.M. (1996). New species of Tomeisneria Roth, Squamoptera Bruijning, and Dethieridris, gen. nov. (Blattaria: Blattellinae and Pseudophyllodromiinae). Oriental Insects 30: 181-192. https://doi.org/10.1080/00305316.1996.10433840

Yanagisawa, S., Hiruta, S.F., Sakamaki, Y., Liao, J.R. \& Shimano, S. (2020). Two new species of the genus Eucorydia (Blattodea: Corydiidae) from the Nansei Islands in southwest Japan. Zoological Science 38: 90-102. doi:10.2108/ zs200048

Yanagisawa, S., Hiruta, S.F., Sakamaki, Y. \& Shimano, S. (2021). A new species of the genus Eucorydia (Blattodea: Corydiidae) from the Miyako-jima Island in Southwest Japan. Species Diversity 26: 145-151. doi:10.12782/specdiv. 26.1450 